\title{
RBEP
}

\section{Contribuições de uma experiência sobre o conteúdo de Tratamento da Informação no programa Pró- Letramento em Matemática}

Neura Maria De Rossi Giusti

Jutta Cornelia Reuwsaat Justo

http://dx.doi.org/10.1590/S2176-6681/291611145

\section{Resumo}

A pesquisa investiga as ações e as contribuições de uma formação continuada nos anos iniciais do ensino fundamental para a prática pedagógica de 18 professores do município de Vacaria, Rio Grande do Sul (RS), envolvendo os conteúdos de Tratamento da Informação (TI), com base no programa Pró-Letramento em Matemática. A pesquisa é qualitativa e tem o estudo de caso como abordagem. A coleta de dados foi composta por questionários, entrevistas, gravações em áudio e análise documental. Os resultados apontaram que a proposta de formação atendeu às expectativas da maioria dos professores de alcançar novos conhecimentos teóricos sobre o conteúdo e seu processo de ensino e aprendizagem, bem como contribuiu para o desenvolvimento de estratégias para a prática pedagógica.

Palavras-chave: educação matemática; formação continuada; letramento; tratamento da informação. 


\section{Abstract \\ Contributions of an experiment about the content of Information Treatment in the Pro-Literacy in Mathematics Program}

The research investigated the actions and contributions of continuing education in the early years of elementary school for the pedagogical practice of 18 teachers in the city of Vacaria, Rio Grande do Sul (RS), involving the contents of Information Treatment (IT), based on the ProLiteracy in Mathematics Program. This qualitative research used the case study approach. The data collection counted on questionnaires, interviews, audio recordings and documentary analysis. The results indicated that the proposal for training has met the expectations of the majority of teachers, in relation to reaching new theoretical knowledge about the content and the process of teaching and learning, as well as contributing to the development of strategies for the pedagogical practice.

Keywords: mathematics education; continuing education; literacy; information treatment.

\section{Introdução}

Avaliações nacionais, como o Sistema Nacional de Avaliação da Educação Básica (Saeb) e o Exame Nacional do Ensino Médio (Enem), e internacionais, como o Programa Internacional de Avaliação de Estudantes (Pisa), registram resultados insatisfatórios na proficiência em matemática de estudantes brasileiros nos diferentes níveis de escolaridade. A baixa qualidade do ensino no País tem impulsionado debates e pesquisas sobre o perfil do professor da educação básica (Unesco, 2004). Essas discussões estão atreladas às transformações econômicas, políticas e sociais, que exigem novos compromissos e conhecimentos desses profissionais. Por essa razão, nos últimos anos, as políticas públicas vêm revalorizando o papel do professor e a importância dos docentes nas estratégias de reforma educacional para a melhoria da qualidade da educação brasileira.

O Ministério da Educação (MEC) investe em programas de formação inicial e continuada para os professores da rede pública, programas esses que nos colocam diante de desafios sobre sua eficácia ou não para atender às atuais demandas de ensino e aprendizagem. Assim sendo, os programas de formação continuada têm a finalidade de aperfeiçoar as práticas pedagógicas desenvolvidas pelos professores para a melhoria da aprendizagem dos estudantes.

Em julho de 2004, foi instituída pelo MEC, como política para a formação de professores, a Rede Nacional de Formação Continuada de Professores de Educação Básica. Entre os programas oferecidos, destacamos o "Pró-Letramento: Mobilização pela Qualidade da Educação", destinado aos professores em exercício dos anos iniciais do ensino fundamental de 
escolas públicas com o objetivo de melhorar a qualidade da aprendizagem da leitura/escrita e da matemática. O curso oferecido tem duração de 120 horas, com encontros presenciais e atividades individuais, sendo realizado no intervalo de oito meses. O MEC elabora as diretrizes, os critérios para a organização dos cursos e a proposta de implementação e garante os recursos financeiros para a elaboração e reprodução dos materiais e para a formação dos orientadores/tutores. Os municípios, por sua vez, disponibilizam professores tutores para desenvolverem o programa em sua região. ${ }^{1}$

Em 2009, ao trabalharmos com o grupo de professores o fascículo cujo tema é Tratamento da Informação (TI), verificamos existir uma carência de conhecimentos referentes a esse bloco de conteúdos, que aborda ideias fundamentais de estatística, probabilidade e combinatória. Ao propormos o tema, surgiram algumas perguntas: "É possível ensinar os alunos a coletar dados e construir gráficos já nos anos iniciais? De que forma eu posso trabalhar em sala de aula?". Diante dessas perguntas, optamos por trabalhar com o fascículo ao longo do curso, por entender que o tema poderia ser contextualizado com os demais conteúdos indicados em outros fascículos e que, por meio das falas dos professores, era pouco ou nada desenvolvido com os alunos dos anos iniciais. Encontramos, assim, a motivação para o desenvolvimento do conteúdo durante todo o curso.

Os trabalhos que os professores realizavam junto aos seus alunos fizeram com que buscássemos indícios que respondessem ao problema da pesquisa: que ações e contribuições uma experiência de formação continuada em serviço pode oferecer à prática pedagógica de professores dos anos iniciais do ensino fundamental do município de Vacaria (RS) sobre os conteúdos de TI?

A seguir, evidenciamos o programa Pró-Letramento: Mobilização pela Qualidade da Educação e o conteúdo de TI. Direcionamos, também, uma discussão sobre a construção da pesquisa. E, por fim, relatamos os dados coletados, abordando as seguintes categorias: concepções e benefícios sobre a formação continuada; conhecimentos, compreensão teórica e prática sobre o conteúdo de TI; situações práticas e aspectos importantes referentes à formação. Desse modo, trazemos algumas considerações sobre as informações coletadas no que diz respeito à formação continuada dos professores, desenvolvida com base no programa em Vacaria (RS).

\section{A formação continuada de professores e o programa Pró- Letramento}

No relatório final sobre formação continuada, Gatti et al. (2011) destacam que, como problemas comuns a diferentes países, estão as ações isoladas, pontuais e de curta duração, que reproduzem as mesmas relações de poder/saber próprias do vínculo escolar. Também prevalecem as formações desvinculadas do contexto de trabalho, sendo poucas as propostas dirigidas aos profissionais. Assim, discutem-se projetos e
${ }^{1}$ No município de Vacaria (RS) a tutora, primeira autora deste trabalho, recebeu capacitação das universidades conveniadas pelo MEC para execução e desenvolvimento do programa. Na primeira etapa do programa (2008/2009), uma universidade gaúcha possibilitou a formação para os tutores dos municípios do Rio Grande do Sul e, na segunda etapa, nomeada como revezamento (2009/2010), uma universidade do Espírito Santo assumiu a coordenação. As universidades proporcionaram orientações e acompanhamento para o desenvolvimento das atividades realizadas pelos tutores dos municípios do Rio Grande do Sul. 
perspectivas de formação continuada que atendam às reais necessidades dos docentes, sob o olhar de diferentes pesquisadores.

Como diz Hernandez (1998, p. 1), "ninguém tem dúvida que a formação docente é um fator essencial para a qualidade da educação". Segundo o autor, o problema surge quando se avalia se houve ou não a transposição didática (Chevallard, 1991). Essa ideia nos reporta aos impactos ou benefícios que uma proposta de formação continuada pode produzir visando mudanças na prática pedagógica.

Hernandez (1998) destaca a importância das propostas de formação e chama a atenção sobre a preocupação de se analisar a maneira como os professores aprendem (ou não). Sugere que

[...] alguém aprende quando está em condições de transferir a uma nova situação (por exemplo, à prática docente) o que conheceu em uma situação de formação, seja de maneira institucionalizada, nas trocas com os colegas, em situações não formais e em experiências da vida diária (Hernandez, 1998, p. 1).

O autor destaca que, no momento de planejar os programas de formação, seria pertinente que os docentes encontrassem respostas para problemas selecionados ou sugeridos por eles mesmos, ou que usassem estratégias de formação que os vinculassem às suas diferentes formas de aprendizagem. Acrescenta que "talvez essa estratégia possa facilitar a sua aprendizagem, mas nunca irá garanti-la totalmente" (Hernandez, 1998, p. 3).

Hernandez (1998) aborda ainda uma perspectiva de formação em que seriam contemplados os seguintes aspectos: considerar que os docentes não partem do zero, pois possuem uma formação e uma experiência durante a qual adquiriram crenças, teorias pedagógicas e esquemas de trabalho; conceituar a prática da formação com base nas experiências concretas e em sua análise, reflexão e crítica; e considerar a formação com fundamento na comparação e no questionamento da própria prática e em relação a outros colegas.

Outra consideração feita pelo autor é que os docentes aprendem não em termos de teorias, mas sim vinculando a aprendizagem à sua prática em sala de aula, ou seja, o que eles poderão usar dentro daquilo que está sendo dito no seu trabalho e até que ponto isso será útil para solucionar seus problemas na prática. No entanto, se tomarmos a formação sob o olhar da praticidade, ela se constituiria em receitas prontas que seriam aplicadas em quaisquer circunstâncias, inclusive naquelas que exigem outras estratégias. Teríamos, assim, uma visão generalista em que a prática ficaria desvinculada da teoria.

Discorrendo sobre o tema, Pimenta e Ghedin (2002) dizem que o saber docente não é só formado de práticas. A teoria tem importância fundamental na formação de docentes, pois dota os sujeitos de variados pontos de vista para uma ação contextualizada, oferecendo perspectivas de análise para que os professores compreendam os diferentes contextos em que se inserem e a si próprios como profissionais. 
Fiorentini e Nacarato (2005) afirmam que o processo contínuo de formação se constitui sob o olhar no qual o professor vê a sua prática como objeto de sua investigação e reflexão, e que os aportes teóricos não são apresentados aos professores, mas buscados à medida que são necessários, contribuindo para a compreensão e a construção coletiva de alternativas para a solução dos problemas da prática docente.

Nóvoa (1992) argumenta que a formação deve estimular uma perspectiva crítico-reflexiva que favoreça o pensamento autônomo e facilite a dinâmica de autoformação participativa; defende práticas de formação coletiva que possam contribuir para a emancipação profissional e a autonomia dos professores; e enfatiza que é necessário articular a formação dos professores com os projetos da escola e que as mudanças devem ocorrer não só na pessoa do professor, mas também no seu local de trabalho: "A formação não se faz antes da mudança, faz-se durante, produz-se nesse esforço de inovação e de procura dos melhores percursos para a transformação da escola" (Nóvoa, 1992, p. 28).

Justo (2009, p. 64) defende a formação continuada de professores em serviço, fundamentada na prática reflexiva. Afirma que essa "é uma temática que preocupa os formadores de professores pela responsabilidade que estes possuem perante a sociedade". Por isso, cada vez mais, "procuram-se estratégias para formar professores competentes e comprometidos, que saibam articular a teoria e a prática". A formação continuada é um espaço de reflexão e troca para o desenvolvimento de uma atitude reflexiva e crítica sobre a prática, numa perspectiva colaborativa capaz de desencadear aprendizagens entre os pares. Desse modo, Imbernón (1994) defende a ideia de que o professor deve envolver-se ativamente em um processo de reflexão crítica acerca do ensino e da aprendizagem, analisando o significado de sua ação.

Perrenoud (2002) delineia a postura reflexiva do professor não apenas com o saber-fazer, mas também com a maneira como ele sabe explicar sua prática e suas decisões. Salienta também que a reflexão sobre a ação pode transformá-la em saberes a serem utilizados em diferentes momentos, à medida que o professor teoriza a própria prática pedagógica.

Gatti et al. (2011) definem a perspectiva colaborativa de formação como aquela em que os professores se reúnem para estudar, realizar questionamentos constantes acerca de sua prática pedagógica e decidir em conjunto o tipo de formação que almejam realizar, especificando sua finalidade e sua forma de implementação. Nessa modalidade, a formação continuada ocorre primariamente nas instituições de ensino ou nas demais dependências do sistema educacional.

O programa Pró-Letramento em Matemática (Brasil. MEC, 2008) foi concebido como uma política de formação continuada de caráter reflexivo que considera o professor sujeito da ação e de suas experiências pessoais. O programa busca compartilhar com os professores práticas pedagógicas e metodológicas para ressignificação do trabalho docente e para o enfrentamento das dificuldades com as quais o professor se depara no dia a dia. 
O Pró-Letramento é destinado aos professores em exercício dos anos iniciais do ensino fundamental de escolas públicas com o objetivo de oferecer suporte à sua ação pedagógica, contribuindo para elevar a qualidade de ensino e aprendizagem nas áreas de leitura, escrita e matemática.

Cada professor recebeu no início do programa um guia composto de oito fascículos: Números naturais; Operações com números naturais; Espaço e forma; Frações, grandezas e medidas; Tratamento da informação; Resolução de problemas e Avaliação em matemática nos anos iniciais (Brasil. MEC, 2008, p. 10).

Os fascículos são desenvolvidos em encontros presenciais onde o grupo de professores desenvolve atividades individuais e coletivas por meio de um roteiro/uma dinâmica de trabalho.

O tutor do grupo faz a mediação entre o professor e o material didático do curso: trabalha com as informações sobre os conteúdos contidas nos fascículos, encoraja os professores a levantarem dúvidas, necessidades especiais de acompanhamento e progressos. Os encontros quinzenais têm a finalidade de oferecer suporte à ação pedagógica dos professores, buscando contribuir para elevar a qualidade de ensino e de aprendizagem em matemática.

\section{O programa Pró-Letramento e o conteúdo de Tratamento da Informação (TI)}

Ao propor nas discussões de formação de professores o tema de Tratamento da Informação (TI), temos a oportunidade de ressignificar o olhar sobre os conteúdos propostos na Matriz de Referência da Avaliação para o Ensino Fundamental/Anos Iniciais (Brasil. MEC, 2008, p. 9). Esse tema permite que os professores tragam para a sala de aula o cotidiano presente nos diversos meios de comunicação, na vida de seus alunos e da escola, além de dotar os alunos de habilidades que poderão ajudá-los a ser participantes críticos para interpretar os aspectos matemáticos e agir com cidadania no ambiente em que estão inseridos. Por isso é tão importante que, desde muito cedo, as crianças tenham contato com esses instrumentos que as ajudam a fazer uma boa leitura do mundo, pois,

Atualmente estamos em contato com muitas informações que precisam
ser interpretadas e compreendidas. Dessa forma, o fascículo 6,
"Tratamento da Informação", apresenta-se com o objetivo de oferecer
condições para você, professor cursista, de construir atitudes críticas
diante de situações da vida cotidiana juntamente com seus alunos e
também abordar ideias fundamentais da Estatística destacando a análise
de dados de tabelas e gráficos (Brasil. MEC, 2008, p. 11).

Como o programa Pró-Letramento em Matemática prevê a utilização do princípio da problematização dos conteúdos e das práticas do cotidiano dos professores para o ensino, seria importante trazer à tona novas leituras e novos enfoques para o tema. 
O Fascículo 6 apresenta algumas sugestões como a leitura, a interpretação de gráficos, a construção de tabelas com base na coleta de dados, as amostragens e, ao mesmo tempo, atividades que envolvem a combinatória e a probabilidade, utilizando conhecimentos matemáticos. O material faz uma breve discussão sobre a importância de se abordar combinatória, probabilidade e estatística de forma integrada e mediante a resolução de problemas.

Para exemplificar o cotidiano escolar, o fascículo sugere diversas atividades para se realizar em sala de aula envolvendo o estudo de estatística, combinatória e probabilidade. Propõe que o professor cursista analise cada atividade e, caso haja necessidade, a adapte à sua realidade. Para finalizar o fascículo sobre o conteúdo de TI, o material instrucional orienta que:

\begin{abstract}
É indispensável saber ler e compreender tabelas e gráficos. Para tal é fundamental estimular os alunos a fazer perguntas, a estabelecer relações, a construir justificativas e a desenvolver o espírito de investigação. Os Parâmetros Curriculares Nacionais alertam que a finalidade desse conteúdo é que os alunos aprendam a descrever e a interpretar sua realidade, e não apenas interpretar as representações gráficas. $\mathrm{Na}$ construção de gráficos é importante verificar se os alunos conseguem ler as informações neles representados. "Para tanto, deve-se solicitar que deem sua interpretação sobre gráficos e propor que pensem em perguntas que possam ser respondidas a partir deles" (Brasil. MEC, 2008, p. 27).
\end{abstract}

O material (Brasil. MEC, 2008, p. 8) orienta que os professores compartilhem as experiências vivenciadas, discutindo as questões mais relevantes desse período em termos das proposições de formação continuada e de sala de aula. Entre as questões possíveis: as dificuldades encontradas na realização das atividades; a relação com o cotidiano; o desenvolvimento profissional e a aprendizagem dos alunos.

\title{
A pesquisa
}

Ao escolher a abordagem qualitativa, aprofundamos as leituras dos autores Fiorentini e Lorenzato (2009), que apresentam referências para a construção de pesquisas em educação matemática.

A opção pela abordagem qualitativa fez com que elegêssemos o estudo de caso como metodologia de pesquisa para analisar uma ação de formação continuada de professores sobre o bloco de conteúdo de TI; a finalidade foi realizar uma reflexão e análise sobre a prática docente de 18 professores para a construção dos conhecimentos sobre esse conteúdo por seus alunos.

A pesquisa desenvolvida assume a modalidade descritiva e interpretativa dos fatos, a qual descreve, caracteriza e compreende os aspectos que compõem a formação continuada de professores. Utilizamos como instrumentos de pesquisa os relatórios, as entrevistas, as gravações em áudio e os questionários. 
Considerando os trabalhos produzidos pelos alunos e professores, buscamos verificar se a formação recebida trouxe benefícios para a prática pedagógica do professor, fazendo uma reflexão e análise sobre a prática profissional para a construção de conhecimentos pelos alunos.

As informações mais significativas foram evidenciadas por meio de transcrição direta das narrativas e falas. ${ }^{2}$ Para preservar a identidade dos professores participantes, trocamos seus nomes por letras do alfabeto: $\mathrm{A}$, B, C, D, E, F, G, H, I, J, L, M, N, O, P, Q, R e S.

\section{Análise dos principais achados}

A análise foi desenvolvida por meio de categorias para que fosse possível evidenciar e agrupar as informações coletadas durante o desenvolvimento da formação. Registramos as informações mais significativas dos professores e, com base nelas, foram versadas seis categorias: (1) concepções sobre formação continuada: finalidade, credibilidade e benefícios que a formação continuada pode trazer para a prática pedagógica; (2) conhecimentos didáticos sobre práticas pedagógicas dos professores referentes ao conteúdo de TI; (3) compreensão teórica do conteúdo de TI; (4) situações práticas, ou seja, a utilização da proposta no contexto de sala de aula; (5) práticas pedagógicas produzidas pelos professores e alunos em sala de aula sobre o conteúdo de TI; e (6) os aspectos que os professores julgaram mais importantes e menos importantes para o êxito de uma proposta de formação continuada.

\section{Concepções de formação continuada}

Perguntamos aos professores: Para você, qual a finalidade da formação continuada de professores? Você acredita que a formação contribui para uma mudança na prática pedagógica? Essas questões forneceram elementos para a análise da categoria concepções, em que foram destacadas a finalidade, a credibilidade e os benefícios sobre a formação continuada.

A intenção não foi definir o que são concepções, crenças ou visões; o que se objetivou foi analisar a importância que os professores dão aos cursos de formação continuada.

\section{Concepções: finalidade, credibilidade e benefícios da formação continuada}

Inicialmente, procuramos compreender a finalidade da formação continuada numa perspectiva de desenvolvimento pessoal e profissional, transcrevendo alguns relatos expressivos a respeito:

[...] penso que a formação continuada serve para estarmos nos atualizando e nos inteirando de assuntos variados, desde os métodos novos, técnicas
${ }^{2}$ Para a transcrição dos textos dos sujeitos investigados, foi adotada a norma ortográfica vigente, sem alterar a forma e o conteúdo do texto transcrito. 
diferentes, troca de ideias, até estar nos atualizando sobre as mudanças com a nossa função: ser professor (Professora E).

[...] porque faz que nós educadores reflitamos sobre nossas práticas pedagógicas. E com isso tornamos o aprendizado do educando cada vez mais aprimorado, porque aprendemos a utilizar os conceitos teóricos cada vez mais práticos e claros (Professora D).

Através da formação, podemos corrigir possíveis erros que cometemos na prática diária em sala de aula, renovamos nossas ideias, ampliamos nossos conhecimentos. Claro que isso só ocorre quando agimos para melhorar nossa prática (Professora N).

Nas falas, percebemos que a formação continuada tem importância significativa na atualização de métodos, conteúdos, técnicas e na troca de experiências entre os professores e, acima de tudo, no desenvolvimento pessoal. Essas falas nos revelam as perspectivas que Chacón (2003) descreve quando menciona as crenças/concepções de natureza de ensino e aprendizagem, ou seja, buscar na formação teorias e metodologias em várias áreas do conhecimento e, consequentemente, pensar a formação como uma prática de possibilidades e de análise crítica sobre o desenvolvimento pessoal e profissional.

Nas narrativas, percebemos o destaque para as expressões "reflexão para a prática pedagógica" e "prática diária de sala de aula". Essas expressões evidenciam o que Nóvoa (1992) enfatiza sobre a valorização de paradigmas: a formação continuada para a promoção de professores reflexivos que assumem a responsabilidade de seu desenvolvimento profissional. A professora $\mathrm{N}$ descreve que depende de o professor melhorar sua prática e colocar os conhecimentos adquiridos em favor dessa tomada de consciência. Ser profissional requer que o professor saiba avaliar criticamente sua atuação e o contexto onde atua.

Percebemos, também, nas narrativas da maioria dos professores pesquisados, o uso de uma prática reflexiva sobre o trabalho docente. Perrenoud acrescenta que a formação pode promover essa tomada de consciência, fazendo com que as práticas possam ser colocadas em palavras, e destaca: "cada um escolherá se deseja retomar suas rotinas ou se vai tentar modificá-las" (Perrenoud, 2002, p. 156).

As professoras $\mathrm{G}$ e $\mathrm{R}$ registram o pensamento da grande maioria dos professores pesquisados quanto à finalidade da formação como a busca do aperfeiçoamento profissional e também pessoal:

Para mim, é buscar aperfeiçoamento profissional [...]. Procuro novos caminhos, formas de levar o conhecimento ao meu aluno. A sociedade nos apresenta desafios constantes e precisamos estar preparados para essas mudanças. No momento em que se adquire um novo conceito, podemos pôr em prática. A formação nos ajuda a repensar, avaliar e projetar nos saberes. Quando nos apropriamos de outros saberes, ele nos leva a novas conquistas, desde que estejamos comprometidos com essa prática (Professora G).

Mudança de atitude e de prática, esta mudança aconteceu devido à conscientização de que minha prática docente estava ultrapassada, 
havendo a necessidade de mudança e de novas ideias. Na formação, o professor terá a oportunidade de crescer profissionalmente e passar os conhecimentos adquiridos para seus alunos, melhorando, com certeza, a qualidade do ensino através de estratégias para buscar as melhores formas de atingir seus objetivos (Professora R).

Percebemos, ainda, as expectativas que as professoras $\mathrm{G}$ e R possuem sobre a formação continuada. Tardif (2002, p. 53) refere-se aos saberes experienciais como uma retomada crítica dos saberes adquiridos na prática. A experiência "filtra e seleciona os outros saberes, permitindo, assim, aos professores reverem seus saberes, julgá-los e avaliá-los e, portanto, objetivar um saber formado de todos os saberes". Os professores, sendo portadores desses saberes, têm na formação continuada a oportunidade de revelar os conhecimentos pedagógicos adquiridos ao longo do tempo e, se tomados como objeto de reflexão, poderão estar a serviço da promoção de um processo educativo voltado para uma aprendizagem consciente e competente.

Outro relato interessante diz respeito à defasagem que ocorre entre a formação inicial e o trabalho docente ao longo dos anos:

Professor desde o primeiro estágio, onde ele percebe as dificuldades dos alunos, seja no aprendizado ou na conduta, e vai buscar soluções para ao menos tentar modificar o quadro apresentado. A formação inicial, às vezes, não auxilia para isso. Depois de anos de experiências, turmas e séries diferentes, percebe que é preciso sempre estar aperfeiçoando o seu trabalho, seja na forma de se expressar, no material que apresenta ou trabalho [...] (Professora C).

Para Nóvoa (1992), Perrenoud (2002) e Tardif (2002), a formação continuada tem como uma das finalidades atenuar a defasagem entre o que os professores aprenderam durante a formação inicial e o que foi acrescentado a partir da evolução dos saberes acadêmicos, dos programas e das reformas curriculares. Cabe ressaltar que a formação continuada vem contribuir para a atualização de saberes docentes como meio de aperfeiçoamento, mas não podemos pensar a formação continuada como instrumento destinado a suprir deficiências causadas na formação inicial.

A seguir, trazemos alguns depoimentos que identificam as concepções relativas à credibilidade que os professores concedem à formação, para uma mudança de prática docente.

A professora $\mathrm{P}$ manifesta sua percepção: "Acredito que a formação continuada vem inicialmente dentro de um processo de melhoria das práticas pedagógicas desenvolvidas pelo professor em sua rotina de trabalho e em seu cotidiano escolar". Assim, a professora P tem a formação continuada como uma conjectura para a melhoria da qualidade do ensino, ou seja, da discrepância entre a formação inicial e os desafios que o cotidiano escolar impõe.

Segundo o relatório final sobre formação continuada (Gatti et al., 2011), esta aparece associada ao processo de melhoria das práticas pedagógicas desenvolvidas no cotidiano escolar para promover a aprendizagem dos alunos. Dentro dessa perspectiva, a formação continuada aparece com um 
forte apelo para a melhoria da qualidade do ensino e, consequentemente, como o fator de impacto nas práticas pedagógicas. Os depoimentos ilustram essas expectativas:

Sim, o professor não deve se acomodar. Sempre inovar suas ideias, buscar novos conhecimentos, se adequar à realidade dos alunos e iniciar um trabalho em cima disso, proporcionando uma prática diária diferente e construtiva para as duas partes (aluno e professor); para tanto, é necessário atualização do conhecimento em cursos de qualidade e voltados à área de atuação, pois o profissional da educação deve ter claro que deve transformar a informação em conhecimento, contribuindo, assim, para a prática pedagógica [...] (Professora P).

Durante a formação, cada professor mentaliza sua turma e tenta encontrar solução para os problemas existentes, dinamizar a aula com ideias novas e se autoavaliar, o que é de suma importância (Professora B).

[...] a partir do momento que você se propõe e se dispõe a participar de uma formação ou curso, é porque você está buscando algo novo para aplicar em seu trabalho. E claro que muitas vezes acabamos por adaptar o que recebemos de novo para o nosso jeito, mas penso que tudo é válido (Professora E).

Se a formação continuada se traduz na busca pela qualidade do ensino, precisamos evidenciar na prática docente tal sentimento - que os efeitos da formação chegam às salas de aula para melhorar o desempenho dos professores e a aprendizagem dos alunos.

A professora A acrescenta outra observação:

Acredito, mas para aquele profissional que esteja aberto às novas mudanças na prática pedagógica. Em outras palavras: tem que querer. $\mathrm{E}$ isso nem todo profissional deseja. Acredito também que nem toda a prática pedagógica nova seja realmente eficaz [...], deve intercambiar com o tradicional, que deu e vem dando certo na aprendizagem, mesmo sabendo que "o nosso aluno" esteja na era digital (Professora A).

O depoimento da professora A nos faz refletir sobre o modo como o professor trabalha, seja ele tradicional ou não, e que vem dando certo, e também sobre a inserção de novas estratégias, metodologias, tecnologias e discursos proporcionados pelos cursos de formação. De acordo com a professora A, a experiência proporcionada ao longo dos anos deve ser valorizada e contextualizada com a nova experiência, de maneira que uma complemente a outra.

Freire sintetiza a formação permanente dos professores na reflexão sobre a prática: "na formação permanente dos professores, o momento fundamental é da reflexão crítica sobre a prática. E pensando criticamente a prática de hoje que se pode melhorar a próxima prática" (Freire, 1996, p. 4344). Isso significa repensar a prática de modo que o conhecimento vá sendo construído diariamente, baseando-se em um processo de reconstrução de saberes pedagógicos.

Na discussão sobre a categoria concepções no que se refere aos benefícios da formação continuada para a prática pedagógica, mencionamos o relato da professora F: 
Durante a formação continuada, há trocas de experiências e relatos de atividades desenvolvidas que tiveram êxito ou não. Assim, buscamos compartilhar ideias com os colegas e confiança, pois muitas vezes conseguimos tirar nossas dúvidas e melhorar nosso trabalho (Professora F).

Como percebemos no relato da professora $\mathrm{F}$, a reflexão crítica sobre as práticas escolares (Freire, 1996, p. 43) incentiva a troca de ideias e experiências com os colegas professores, a realização de leituras, a utilização de recursos em diferentes espaços e suportes didáticos. Pensar em um curso de formação continuada de professores é levar em consideração o saber que cada professor traz de sua prática docente.

A professora P contribui argumentando que:

Na formação continuada de matemática de que participei, eu pude esclarecer várias dúvidas significando práticas e conteúdos, visualizando de outras formas os conteúdos a serem desenvolvidos na série, onde pude repensar várias formas de conteúdos, onde estes novos olhares e formas de apresentar os conteúdos facilitaram a aprendizagem dos alunos. Também a oportunidade de discussões com o grupo das práticas desenvolvidas, estando os mesmos num guia com várias sugestões e principalmente embasamento teórico para entender a necessidade da construção do conhecimento pelo aluno com a mediação do professor (Professora P).

Fiorentini (2008, p. 60) menciona que a formação é um processo contínuo de reflexão interativa e contextualizada sobre as práticas pedagógicas e docentes na articulação entre teoria e prática, numa relação de parceria entre formadores e formandos, em que ambos podem interagir colaborativamente, sendo corresponsáveis pela resolução de problemas e desafios da prática e pela produção conjunta de saberes relativos às práticas educativas.

\section{Conhecimentos didáticos e práticas pedagógicas sobre o conteúdo de TI}

Nesta categoria, foi solicitado aos professores que relatassem seus conhecimentos prévios: No que se refere aos conhecimentos didáticos e às práticas pedagógicas sobre o conteúdo de TI, que conhecimentos você possuía antes da formação?

Citamos alguns relatos de professores:

[...] não se tinha um conhecimento significativo, apesar de já ter trabalhado algumas vezes com atividades relacionadas ao assunto. $\mathrm{O}$ assunto TI chegou em boa hora, para conseguirmos compreender bem todas as informações em que somos envolvidos. Os gráficos e as tabelas nos auxiliam a coletar, organizar, comunicar e interpretar dados utilizados em diversos registros. Esses conhecimentos, além de fornecerem os processos de crescimento pessoal, objetivam dotar os alunos de habilidades que os ajudarão no ambiente em que estão inseridos (Professora J). 
Eu acreditava que a probabilidade e a estatística eram conteúdos para grandes estudiosos; hoje, na verdade, eu percebo que eles estão bem presentes em nosso dia a dia e especialmente que eles podem ser bem trabalhados com os alunos de séries iniciais, e que estes conteúdos podem ir ao encontro da realidade dos alunos (Professora L).

Os relatos das professoras $\mathrm{J}$ e L evidenciam que os conhecimentos didáticos e pedagógicos sobre o conteúdo de TI eram incertos e precários. Isso caracteriza a resistência de trabalhar o conteúdo em sala de aula, e sem conhecer profundamente ficaria difícil pensar em formas de ensiná-lo. Outro aspecto percebido nos relatos é a falta de informação e experiência para o desenvolvimento do conteúdo, fazendo com que, muitas vezes, o professor prefira não trabalhar com esses temas em suas aulas. O relato da professora $\mathrm{C}$ é revelador sobre esse aspecto:

Basicamente você não tem a noção do conteúdo TI. São complicados, difíceis e que dão trabalho, não vou fazer! Porém você percebe durante o curso que se você utiliza dados reais de situações reais e cotidianas tudo fica mais coerente e prático. Você desafia o aluno a observar, analisar, perceber a diferença e a semelhança e agrupar as respostas. Exemplo: meninas com cabelo curto, meninos com olhos claros. Você tem várias práticas para questionar e fazê-los concluir sobre os resultados. Hoje considero o conteúdo fácil (Professora C).

É possível identificar nessa fala indícios da deficiência de conhecimentos sobre o conteúdo. Nesse caso, a formação continuada pode ter contribuído para a apropriação do conteúdo no que se refere aos conceitos matemáticos, à compreensão e à prática educativa.

Shulman (1986) referencia o "conhecimento específico do conteúdo", ressaltando que o simples domínio do conhecimento do conteúdo específico não garante, por si só, um ensino eficaz. Há de se considerar a forma como os professores transformam o conhecimento que possuem da matéria a ser ensinada para os alunos. O conhecimento específico pode influenciar o conhecimento pedagógico do conteúdo.

Estimamos que a maioria dos professores envolvidos na pesquisa apresenta características comuns: dificuldades de conhecimento específico e pedagógico do conteúdo matemático. A falta desses conhecimentos, de acordo com alguns relatos mencionados dentro dessa categoria, pode ter contribuído para a ausência do desenvolvimento do bloco de conteúdos nos anos iniciais do ensino fundamental.

Fiorentini (1995, p. 1-37) reconhece que o domínio da matéria de ensino é fundamental para que o professor tenha autonomia intelectual para produzir conhecimento, e a forma como o professor conhece e concebe o conteúdo de ensino tem fortes implicações no modo como seleciona e reelabora o saber escolar, especialmente no modo como explora e problematiza suas aulas. 


\section{Compreensão teórica e prática}

Na categoria compreensão teórica e prática sobre o conteúdo de TI, buscamos evidenciar se os assuntos discutidos na formação continuada contribuíram ou não para ampliar e/ou transformar os conhecimentos do professor no que se refere ao processo educativo. Apresentamos alguns depoimentos:

Sim. A prática, o fazer, torna a teoria menos alheia à sala de aula. É uma prova de que a nossa prática pedagógica precisa ter uma base teórica e uma fundamentação correta (Professora C).

Com certeza, pois, além de compreendermos teoricamente, tivemos oportunidade de pôr em prática com atividades de sala de aula (Professor I).

Sim, pois foram abertas novas janelas de como trabalhar os conteúdos que até então eram vistos como complicados de ensinar pela dificuldade que os alunos tinham em compreendê-los (Professora F).

Os relatos registram que é possível a formação ter contribuído para uma compreensão teórica e prática sobre o conteúdo de TI. Chama-nos a atenção o registro da professora $\mathrm{F}$, em que descreve que o conteúdo era visto como "complicado de ensinar pela dificuldade que os alunos tinham em entendê-los". Presumimos que a ausência do conhecimento específico e didático tenha contribuído para a dificuldade de compreensão do conteúdo por parte desses alunos e da própria professora.

Entendemos que o conhecimento específico do conteúdo incide sobre o conhecimento pedagógico, mas faz-se necessário refletir que a formação não se consolida só por meio da transmissão de conteúdos. Segundo Perrenoud (2002, p. 78), a formação se dá por meio do envolvimento crítico, da construção de experiências formativas, pela aplicação e estimulação de situações de aprendizagem. Se tomarmos essa postura reflexiva sobre a ação e sobre os saberes teóricos e metodológicos, podemos revelar algumas atitudes positivas e seguras frente ao conteúdo a ser desenvolvido.

Outro aspecto a ser revelado foram as falas paralelas dos professores. Nos momentos presenciais da formação, foi evidenciado o desejo de os professores se apropriarem de informações sobre o conteúdo. Entre as falas, destacamos o relato das professoras E e I:

[...] para começar a valorizar esses conteúdos, que antes eram vistos superficialmente, e agora percebi que posso trabalhar os conteúdos do currículo envolvendo o TI (Professora E).

[...] o assunto faz parte do nosso dia a dia e pode ser aplicado em diversas situações (Professora I).

Percebemos nos relatos as lacunas relativas ao conteúdo e o desejo de se apropriar do conhecimento específico e pedagógico. Entretanto, os professores, conscientes de suas limitações, buscam oportunidades 
de formação que lhes permitam compreender melhor os conteúdos que ensinam, como no caso dos professores envolvidos neste estudo.

Verificamos que há profissionais, no caso os professores pesquisados, que não temem a "zona de risco". A zona de risco, segundo Skovsmose (2008, p. 49), deve ser entendida como um espaço de possibilidades e de novas aprendizagens, do qual o professor não deve recuar.

Um dos possíveis motivos que faz com que os professores não utilizem o conteúdo TI é o fato de que esse bloco de conteúdos muitas vezes exige que o professor passe pelo processo de transição entre a zona de conforto e a zona de risco, ${ }^{3}$ de modo que ele deixe de trabalhar de maneira habitual e se insira em um ambiente em que reveja e amplie seu conhecimento constantemente.

\section{Situações práticas}

Nesta categoria evidenciamos as práticas pedagógicas produzidas pelos professores e alunos em sala de aula sobre o conteúdo de TI, considerando a formação desenvolvida.

Os professores foram indagados a respeito da questão: Você já utilizou as propostas de ensino sobre o conteúdo TI abordadas na formação em sala de aula? Se sim, quais?

Primeiramente, evidenciaremos a aplicação do conteúdo em sala de aula e, a seguir, quais foram as práticas sobre o conteúdo de TI.

Encontramos relatos afirmativos que evidenciam práticas positivas e seguras no desenvolvimento do tema. Segundo a professora E, ao trabalhar com o conteúdo de TI,

Os alunos se interessaram mais, porque estavam trabalhando com situações e informações que eles vivem e conhecem e, a partir desses assuntos, podemos englobar os demais conteúdos que nem sempre são atrativos aos alunos. O conteúdo passou a ser "mais valorizado", pois antes era visto superficialmente no currículo escolar e pelos colegas professores. Agora percebi que posso trabalhar conteúdos do currículo em cima dos conteúdos de tratamento da informação. Utilizo os conteúdos do TI de uma maneira que possamos tratar os assuntos da atualidade, fazendo com que os alunos interpretem, compreendam e adquiram conhecimentos para aplicar em sua vida, em situações do cotidiano (Professora E).

A fala da professora E está em acordo com Lopes e Carvalho (2005), que afirma que de nada adianta os estudantes realizarem atividades relacionadas ao conteúdo se este não for feito para solucionar situações que tenham sido problematizas por eles, ou seja, se não aproveitar os interesses reais dos alunos para coletar e organizar o conjunto de dados que servirão de base para o trabalho que se irá realizar ao longo da unidade.

A professora J informa que, no início da aplicação do conteúdo, os alunos apresentavam bastante dificuldade para montar gráficos e tabelas: "No começo, era difícil até para nós professores. Fomos orientados e agora

\footnotetext{
${ }^{3}$ Penteado (1999) considera que é difícil para os professores deixarem de trabalhar da maneira considerada tradicional (zona de conforto) e se inserirem em um ambiente no qual é solicitado deles que revejam e ampliem o seu conhecimento constantemente (zona de risco).
} 
percebo que os alunos possuem habilidades e fazem sozinhos. Todo o conteúdo dado, os alunos pedem para fazer gráficos" (Professora J).

Considerando essa fala, reportamo-nos a Shulman (1986), quando se refere ao conhecimento pedagógico do conteúdo, afirmando que esse conhecimento se faz no interior das práticas pedagógicas escolares, na capacidade de o professor transformar o conhecimento que possui em atividades pedagógicas adequadas à variedade, às habilidades e aos contextos apresentados.

A professora E acrescenta:

Após a formação, muita coisa mudou, tanto na minha maneira de pensar quanto na minha atuação em sala de aula. Com os esclarecimentos dados na formação, comecei a perceber a matemática como algo mais importante do que já era. Consegui trabalhar de maneira criativa e menos complicada, pois com tantas explicações percebi o prazer da matemática e, assim, consigo passar para meus alunos. Antes da formação, tratava o conteúdo TI como sendo a aplicação de situações-problemas, buscando envolver a realidade da vida de minha turma, desafios matemáticos, mas confesso que na maioria das vezes trabalhei sempre voltada para vencer conteúdos, não fazendo uma relação do conteúdo com a vida real, assim não alcançando o principal objetivo de ensinar: fazer com que o aluno encontre um significado para o que está aprendendo, uma utilidade, uma explicação em sua vida e para quê aprendeu (Professora E).

O destaque nessa fala nos faz refletir sobre a prática escolar. Percebemos que a formação continuada contribui para uma mudança de postura profissional em face do conteúdo, do ensino e da aprendizagem do aluno.

Já a professora B afirma que trabalhar com o conteúdo de TI "Exige algumas metodologias de nível elevado para as crianças, mais apropriado para a formação do professor do que para os alunos". Segundo ela, a utilização do conteúdo foi pouca, mas informa que "a parte mais usada do conteúdo e adequada ao nível dos meus alunos foi a probabilidade" (Professora B).

Essa narrativa reforça o entendimento de que a construção dos saberes experimentais dos alunos tem origem na prática cotidiana do professor no saber-fazer e no saber-agir. Tal como as observações, emite julgamentos de acordo com a situação e o contexto. Para delinear essas experiências, lembramos Nóvoa (1992), referindo que essas formas identitárias estão entrelaçadas ao processo de formação docente no qual os professores elevam o seu rendimento e aumentam seu poder de autonomia apoiando-se cada vez mais nas suas experiências e capacidades adquiridas ao longo do seu percurso de vida.

Lopes (2010, p. 61) enfatiza que a implantação curricular da estatística e da probabilidade depende de um investimento significativo dos educadores no que se refere à formação inicial e continuada, à elaboração de livros didáticos que contemplem esses conteúdos e a publicações que subsidiem o trabalho docente do professor da educação básica. 


\section{Práticas pedagógicas}

A seguir, pontuamos situações práticas de sala de aula sobre o conteúdo de TI em que podemos confirmar algumas atividades desenvolvidas e demonstradas pelos professores nos encontros presenciais do grupo de estudos e relatadas aos demais participantes. Entre as atividades, destacamos:

\section{Como você vai para a escola?}

A professora I propôs aos alunos do $4^{\circ}$ e do $5^{\circ}$ ano a seguinte situação: Como você vai para a escola? Com essa atividade, a professora queria evidenciar o meio de locomoção dos alunos, pois a escola em que leciona localiza-se numa área rural de difícil acesso para eles. A pedido dos demais professores que lecionam na mesma escola, a professora estendeu a proposta para o $1^{\circ}$, o $2^{\circ}$ e o $3^{\circ}$ anos do ensino fundamental. A professora, juntamente com os alunos, construiu um gráfico de barras em que eles poderiam organizar e interpretar os dados coletados com base em uma situação real.

[...] pensei numa atividade relacionada mais ao cotidiano deles. Pensei no meio de locomoção, como eles vão para a escola. Como é escola da zona rural, muitos utilizam transporte, outros moram na comunidade. A princípio, pensei em fazer com minha turma, mas como na escola todo mundo se envolve, então surgiu a ideia de fazer com todas as turmas da escola. Até os professores e a merendeira entraram no meio de locomoção até chegar à escola. Lá [...], primeiramente, muitos disseram que vêm com o "ônibus grande", com o micro, eles lembraram da Kombi. Ah! [...] muitos lembraram que as professoras vêm de carro, então vamos colocar o carro. E os que moram pertinho vêm a pé. Comecei com minha turma, em que cada um tinha um papelzinho com seu nome e ia colando de acordo como eles vinham. [...] Depois passamos de turma em turma, e eles iam colando. Tiramos as conclusões: quantos alunos a mais e a menos, de acordo com o meio de locomoção; quem mora mais longe e mais perto; a distância entre as localidades; quem mora no meio do caminho; a professora, o percurso que ela faz até chegar à escola; e fomos, assim, fazendo o questionamento oralmente e depois fomos para a atividade no caderno (Professora I).

A professora I oportunizou aos alunos o aprendizado com base em uma situação real, vivenciada pelos alunos daquela localidade. Possibilitou o estudo matemático, a análise do problema por meio de intervenção positiva, abrangendo conhecimentos de estatística, de modo que os alunos pudessem coletar informações, organizá-las e representá-las na forma de gráficos e tabelas, além de interpretá-las criticamente. A professora construiu com seus alunos procedimentos de coleta e organização, para comunicar e interpretar dados a partir de uma situação real. Além disso, houve a oportunidade de fazer um comparativo significativo entre as distâncias das localidades do município e os mais diferentes meios de locomoção. 
Outra ação que merece destaque é a da professora L, que desenvolveu com os alunos uma atividade envolvendo a combinatória. A professora comenta:

Professora: - Com a chegada do inverno, a gente precisa de mais roupas e agasalhos - então eu fiz uma matriz de menina e uma matriz de menino com roupas. Para as meninas eu dei mais roupas, mais quantidade do que para os meninos.

Alunos: - [...] Por que as meninas ganharam mais?

Professora: - Por que as meninas ganharam mais?

Aluno: - Porque as mulheres trocam mais de roupa!

Professora: - É que mulher gosta mais de combinar as roupas - em seguida eles pintaram e começaram a combinar as roupas como calças, casacos e toucas. E então pedi como nós podemos combinar as roupas. Alunos: - Essas roupas dão pra combinar em três dias mudando toda a roupa.

Então eles começaram a pensar.

Professora: - Ah! [...] dá prá combinar a mesma calça e o mesmo casaco, só mudar a cor, trocando uma peça de roupa - pedi para eles colocarem a ideia no papel. - [...] Pra vocês entenderem que no $2^{\circ}$ ano conseguiram entender essa ideia do que era combinação e viram também que as meninas tinham mais maneiras de combinar as roupas - aproveitei também a atividade para trabalhar as medidas do tempo. Foi essa a ideia (Professora L).

A professora L, ao desafiar seus alunos baseando-se em uma situaçãoproblema, propiciou noções sobre combinatória, ou seja, noções sobre o princípio multiplicativo e de contagem. A combinatória, nesse sentido, vem como um elemento auxiliar na aprendizagem de matemática, em que a finalidade é fazer com que o aluno compreenda acontecimentos do cotidiano, de natureza aleatória, nos quais se identifiquem possíveis resultados e até se estimem possibilidades acerca deles. Fazer com que os alunos lidem com situações que envolvam diferentes tipos de agrupamentos possibilita o desenvolvimento do raciocínio e do cálculo.

A professora L menciona que os alunos gostaram da atividade, que foi divertida e que todos tiveram a oportunidade de participar e construir seu material, levando para casa o que tinham feito. A professora relata: "foi bom perceber que os alunos podem estudar matemática de uma forma divertida e lúdica".

\section{O sítio de seu Lobato}

A atividade foi realizada pelos alunos do $4^{\circ}$ ano do ensino fundamental com o auxílio da professora E. Nessa atividade, os alunos deveriam construir com um grande grupo a história de "O sítio de seu Lobato", que consistia na criação de uma história matemática em que os alunos realizassem atividades que envolvessem a leitura, a interpretação e a construção de um gráfico para a resolução de problemas matemáticos. 
Os alunos, ao construírem uma história matemática sobre um pequeno sítio cujo proprietário dedicava-se à criação de animais e ao plantio de árvores frutíferas, descreveram situações do dia a dia do senhor Lobato. Situações como compra e venda de produtos do sítio, planejamento para plantio, projeto da casa do proprietário, entre outras. Para o desenvolvimento da atividade, diferentes conteúdos foram evidenciados: resolução de problemas envolvendo as quatro operações matemáticas, geometria, áreas, construção de tabelas e gráficos, utilização de instrumentos de medida, etc. A atividade, de acordo com a professora, contribuiu para a verificação dos conteúdos trabalhados na série, mas, também, para "a construção de noções de estatística com tratamento de informações, a partir da construção de gráfico utilizando papel quadriculado e régua" (Professora E).

\section{Alfabeto dos nomes}

A professora $\mathrm{J}$ realizou com os alunos do $1^{\circ}$ ano a atividade que denominou de "Alfabeto dos nomes". Propôs aos alunos a criação do alfabeto com base na construção de um gráfico em que os alunos identificam as letras com a inicial de seus nomes. Entre as atividades sugeridas para a turma, a professora explorou, além do alfabeto, os números naturais e as operações de adição e subtração. Entre as perguntas para a realização da atividade, estavam as seguintes: "Quantas letras tem o teu nome? Quais são as letras? Quantas sílabas? Quantos nomes de colegas iniciam com a letra A? E com a letra B? Quantos colegas não iniciam os nomes com a letra $\mathrm{C}$ ?" E assim sucessivamente. A professora J relata que os questionamentos foram realizados oralmente e que os registros dos cálculos foram transcritos para o caderno de aula.

Analisando a atividade pedagógica desenvolvida pela professora, reportamo-nos aos PCN (Brasil. MEC, 1997). De acordo com o documento, nos anos iniciais de escolarização, é possível realizar atividades voltadas ao desenvolvimento de competências e habilidades para coletar, organizar e analisar dados, bem como para a capacidade de ler, interpretar e estabelecer relações.

Gostaríamos de contemplar todas as atividades desenvolvidas pelos professores e seus alunos durante o processo de formação, porém, neste trabalho, optamos por descrever algumas.

\section{Aspectos importantes}

Nesta categoria mencionamos os aspectos que os professores julgam mais importantes e menos importantes para o êxito de uma proposta de formação continuada em serviço: os aspectos relacionados à seleção dos temas, à gestão do tempo destinado aos trabalhos, aos procedimentos metodológicos utilizados, às atividades propostas, à mediação do professor tutor, à participação geral dos professores e ao alcance na prática da sala de aula. 
Os professores participantes da formação deveriam numerar de 1 a 7, em ordem de importância, os aspectos elegidos e justificar o porquê de serem mais ou menos importantes. ${ }^{4}$

\section{Aspectos mais importantes}

Mencionamos as narrativas dos professores que evidenciam aspectos importantes para uma proposta de formação continuada.

\section{- Seleção dos temas}

Para uma proposta de formação continuada de professores, a seleção dos temas ou conteúdos a serem desenvolvidos torna-se relevante para a escolha da formação? Como se dão as escolhas dos professores para a participação em cursos de formação? Pontuamos os relatos:

Sempre devem estar e vir ao encontro das dificuldades (Professora A).

É de suma importância, pois o tema deve ser de acordo com o que você trabalha e estar ao encontro da sua ansiedade na sala de aula (Professora B).

Os temas abordados vão ao encontro de algumas dificuldades que temos e buscamos na formação encontrar solução (Professora C).

[...] é bom quando você vai a uma formação onde se é tratado sobre matemática da série que está atuando, por exemplo (Professora E).

Tenho que saber quais os conteúdos ou temas para, a partir disso, elaborar o planejamento mais adequado ou atingir o objetivo da formação [...] (Professora P).

É muito importante, primeiramente, qual o conteúdo que se vai trabalhar (Professora Q).

O professor é responsável ao planejar suas atividades, saber qual será o tema (Professora R).

Diante dos relatos apresentados, realizamos algumas reflexões. Na fala da professora B, fica evidente que o processo de escolha da formação deve vir no momento em que a professora se encontra, para minimizar a sua ansiedade sobre o que ela está trabalhando ou, conforme a professora E, vir ao encontro da série em que ela atua.

Percebemos nos relatos que o processo de escolha da formação está vinculado ao estabelecimento de uma correspondência entre o processo vivenciado pelo professor e o momento em que, então, ele se encontra. A essa perspectiva, Hernandez (1998) faz referência quando diz que o professor percebe a formação vinculada à aprendizagem e o que ele poderá usar dentro daquilo que está sendo dito no seu trabalho, e até que ponto isso será útil para solucionar seus problemas na prática.
${ }^{4}$ Ordem de importância: 1 mais importante; 7 - meno importante. 


\section{- Alcance na prática}

Pontuamos como os professores realizam o processo de escolha de formação no que se refere às práticas pedagógicas oferecidas pelos cursos. Apresentamos os registros:

Importante, pois o principal objetivo dos cursos de formação continuada é aprimorar nossas práticas de sala de aula. (Professora D).

É o item mais importante, afinal, só podemos qualificar nosso trabalho quando temos sugestões que possam ser aplicadas em sala de aula (Professora I).

Porque é um item muito importante. Eu busco realmente uma formação que me ajude qualificar e melhorar minha prática em sala de aula, e acima de tudo que melhore a aprendizagem de meus alunos (Professora L).

As falas ilustram a importância que a formação adquire para as práticas pedagógicas das professoras. A professora I a menciona como o item mais importante no processo de formação. De acordo com Hernandez (1998), a ideia de que o professor é, principalmente, um prático, vem adquirindo força com o passar dos tempos. Uma das considerações que o autor destaca é que quando os professores aprendem, vinculam a aprendizagem à sua prática em sala de aula, ou seja, o que poderá usar, dentro daquilo que está sendo dito, no seu trabalho, e até que ponto isso será útil para solucionar seus problemas na prática.

A procura por cursos de formação que contemplem a prática pedagógica - o alcance na prática - foi o segundo aspecto mais pontuado pelos professores pesquisados. Diante disso, trazemos as reflexões de Imbernón (2010), quando argumenta que as práticas formativas que promovem demonstrações e/ou simulações de práticas vividas pelos professores podem ser realmente significativas, caso consigam ultrapassar a fase de explicação. Nesse sentido, pensamos que as práticas formativas implicam um acompanhamento para a viabilização da formação; acompanhar como está sendo aplicado na sala de aula e, com base na avaliação, ver o que ainda não está entendido sobre a proposta a ser ensinada, o que ainda é necessário para que se tenham resultados efetivos para a aprendizagem de professores e alunos. Assim sendo, ações pontuais tendem a ser insuficientes e descomprometidas quando se pretende promover mudanças duradouras nas práticas pedagógicas e aprimorar a qualidade da educação oferecida.

\section{Aspectos menos importantes}

Destacamos os aspectos que os professores julgam de menor importância para o êxito de uma proposta de formação continuada e as narrativas que justificam a escolha. 
No que se refere à participação geral dos professores em um curso de formação, trazemos alguns relatos:

A participação geral dos professores não apresenta um bom rendimento. Pequenos grupos e direcionados para a formação específica (Professora A).

Não adianta ter um número grande de professores se não há interesse de todos. Deve fazer a formação quem realmente tem interesse em se aperfeiçoar (Professora B).

Numa formação continuada, a participação geral pode atrapalhar o bom rendimento do grupo, mas não te impede de estar atento, de fazer, refazer e de querer melhorar a prática (Professora C).

Porque em alguns momentos há muitas conversas (Professora M).

É importante também, pois, todos participando da formação, teremos cultura de formação continuada elevando a qualidade de ensino. (Professora P).

De acordo com os relatos, há duas posições distintas: professores que defendem que a constituição de pequenos grupos de estudos proporciona um melhor aproveitamento para a formação, e professores que defendem que a participação geral enriquece e eleva a qualidade da formação.

Conforme relatam as professoras A, B, C e M, a participação geral pode implicar uma iniciativa forçada de participação descomprometida diante do real sentido da formação, gerando conversas paralelas e falta de interesse. Por outro lado, iniciativas próprias dos professores podem configurar um melhor aproveitamento da formação.

Outrossim, trazemos a seguinte ideia quanto à participação geral dos professores nos cursos: a promoção de formações como via de discussão entre os pares pode ser estabelecida como uma forma ou estratégia que permite o entrosamento dos professores nos diferentes níveis de experiência e de ensino, com o objetivo de discutir e aprimorar processos de ensino e aprendizagem.

- A gestão do tempo destinado aos trabalhos

A gestão do tempo destinado para a formação foi o segundo aspecto de menor importância pontuado pelos professores. Registramos alguns relatos:

O tempo não é tão importante, pois o primordial ao se fazer o curso deve ser ter disponibilidade de tempo, seja na hora do trabalho ou não (Professora D).

O tempo deve ser adequado ao curso e às atividades propostas (Professora J).

Muitas vezes o tempo é curto para o desenvolvimento da atividade e a troca de experiências (Professora I). 
Muitas vezes, a gestão do tempo nos cursos de formação impede ou dificulta a escolha ou o êxito de um programa de formação continuada. Segundo o relatório final de formação continuada (Gatti et al., 2011), a escolha dos cursos de formação de curta duração revela a opção frequente entre os professores e as secretarias municipais e estaduais brasileiras.

\section{Considerações finais}

Analisando os resultados, percebemos que os conhecimentos didáticos e pedagógicos sobre o conteúdo de TI eram incertos e precários; que a formação possibilitou atitudes mais seguras das práticas pedagógicas sobre o conteúdo de TI; que a reflexão sobre a prática permitiu aos professores a (re)construção e ressignificação dos conhecimentos teóricos e práticos sobre o bloco de conteúdo em estudo; que o conhecimento profissional deriva da integração entre teoria e prática; que as experiências vivenciadas servem como ponto de partida para reflexões sobre as práticas pedagógicas; que possuir conhecimentos do conteúdo e conhecimentos pedagógicos sobre o que se ensina dependerá da pessoa do professor e de seu envolvimento intencional; que o desenvolvimento pessoal e profissional emerge da transição entre a zona de conforto e a zona de risco; e que os aspectos significativos dos conhecimentos matemáticos no que se refere ao bloco de conteúdos de TI foram resultantes do trabalho de grupo de estudos entre os professores num processo colaborativo de reflexões sobre a prática.

Ao tecer diferentes questões sobre a formação, realizamos também reflexões com o objetivo de fortalecer e aprimorar as ações de formação por parte das políticas públicas. Entre as reflexões, destacamos: que exista um planejamento que contemple a formação continuada de qualidade para os professores dos anos iniciais, com carga horária apropriada, para que a maioria dos professores possa realizá-la em serviço; que as práticas pedagógicas sejam discutidas entre os pares, num processo reflexivo que leve em conta os saberes e as experiências dos professores; que as formações não sejam apenas pontuais e desvinculadas da realidade da escola; que se crie a cultura de formação por meio de políticas públicas e que os mecanismos e instrumentos de formação estejam alicerçados na reflexão sobre a prática e na ampliação de conceitos e fundamentados na teoria que sustenta o trabalho educativo.

Acreditamos que o programa Pró-Letramento atingiu seus objetivos, pois, além de atualizar e instrumentalizar os professores, produziu efeitos positivos nas práticas de ensino e aprendizagem da matemática sobre o conteúdo de TI. Promoveu atitudes equilibradas entre a teoria e a metodologia de ensino e, principalmente, fundamentou seus estudos nas experiências e no saber acumulado para o enfrentamento dos desafios cotidianos.

Sendo assim, a pesquisa constatou por parte dos professores cursistas a aprovação expressiva do Pró-Letramento, oferecido pelo MEC, pois segundo eles a proposta de formação está bem estruturada, o material instrucional 
bem diversificado e, além disso, o programa oferece material sugestivo para a prática pedagógica, a fim de promover um ensino efetivo e de qualidade.

Os professores participantes do programa Pró-Letramento vivenciaram uma formação por meio de grupo de estudos colaborativo, em que tiveram a oportunidade de construir e reconstruir suas concepções sobre a formação de professores. Para tanto, é primordial que cada professor esteja aberto a novas ideias, ciente de que não existe verdade absoluta e de que precisa rever suas ações constantemente, concebendo a própria formação como um dos componentes entre outros setores e áreas de mudança.

Acreditamos que essas informações sejam importantes para subsidiar o fortalecimento de novos paradigmas de formação continuada capazes de propiciar o aprimoramento pessoal e profissional dos professores e melhorar a qualidade da educação oferecida pelas redes públicas de ensino.

\section{Referências bibliográficas}

BRASIL. Ministério da Educação (MEC). Secretaria de Educação Fundamental (SEF). Parâmetros Curriculares Nacionais: matemática. Brasília, DF: SEF/MEC, 1997. 142 p.

BRASIL. Ministério da Educação (MEC). Secretaria de Educação Básica (SEB). Pró-letramento: programa de formação continuada de professores dos anos/séries iniciais do ensino fundamental: matemática. Brasília, DF: SEF/MEC, 2008.

CHACÓN, I. M. G. Matemática emocional: os afetos na aprendizagem matemática. Porto Alegre: Artmed, 2003.

CHEVALLARD, Y. La transposition didactique: du savoir savant au savoir ensigné. Grenoble: La Pensée Sauvage, 1991.

FIORENTINI, D. Alguns modos de ver e conceber o ensino da matemática no Brasil. Zetetike, Campinas, v. 3, n. 4, p. 1-37, 1995.

FIORENTINI, D. A.; NACARATO, A. M. (Org.) Cultura, formação e desenvolvimento profissional de professores que ensinam matemática: investigando e teorizando a partir de prática. São Paulo: Musa, 2005.

FIORENTINI, D. A. A pesquisa e as práticas de formação de professores de Matemática em face as políticas públicas no Brasil. Bolema, Rio Claro, v. 21, n. 29, 2008.

FIORENTINI, D.; LORENZATO, S. Investigação em educação matemática: percursos teóricos e metodológicos. Campinas, SP: Autores Associados, 2009. 
FREIRE, P. Pedagogia da autonomia: saberes necessários à prática educativa. 3. ed. Rio de Janeiro: Paz e Terra, 1996.

GATTI, B. A. et al. Formação continuada de professores: uma análise das modalidades e das práticas em estados e municípios brasileiros: relatório final. São Paulo: Fundação Carlos Chagas, 2011. Disponível em: <www. fvc.org.br/estudos >. Acesso em: 23 jul. 2011.

HERNANDEZ, F. A importância de saber como os docentes aprendem. Pátio Revista Pedagógica, Porto Alegre, fev./abr. 1998.

IMBERNÓN, F. La formación del professorado. Buenos Aires: Paidós, 1994.

IMBERNÓN, F. Formação continuada de professores. Porto Alegre: Artmed, 2010.

JUSTO, J. C. R. Resolução de problemas matemáticos aditivos: possibilidades da ação docente. 2009. $197 \mathrm{f}$. Tese (Doutorado em Educação) - Faculdade de Educação, Universidade Federal do Rio Grande do Sul, Porto Alegre, 2009.

LOPES, C. A. E. Os desafios para educação estatística no currículo de Matemática. In: LOPES, C. A. E.; COUTINHO, C. Q. S.; ALMOULOUD, S. A. (Org.). Estudos e reflexões em educação estatística. Campinas, SP: Mercado de Letras, 2010. p. 47-64.

LOPES, C. E.; CARVALHO, C. Literacia estatística na educação básica. In: NACARATO, A. M.; LOPES C. E. (Org.). Escritas e leituras na educação matemática. São Paulo: Autêntica, 2005. p. 77-92.

NACARATO, A. M.; LOPES, C. A. E. (Org.). Escritas e leituras na educação matemática. Belo Horizonte: Autêntica, 2005.

NÓVOA, A. Formação de professores e profissão docente. In: NÓVOA, A. (Coord.). Os professores e a sua formação. Lisboa: Publicações Dom Quixote, 1992. p. 13-33.

UNESCO. O perfil dos professores brasileiros: o que fazem, o que pensam, o que almejam. São Paulo: Moderna, 2004.

PENTEADO, M. G. Novos atores, novos cenários: discutindo a inserção dos computadores na profissão docente. In: BICUDO, M. A. V. (Org.). Pesquisa em educação matemática: concepções e perspectivas. São Paulo: Ed. Unesp, 1999.

PERRENOUD, P. A prática reflexiva no ofício do professor. Porto Alegre: Artmed, 2002. 
PIMENTA, S. G.; GHEDIN, E. (Org.). Professor reflexivo no Brasil: gênese e crítica de um conceito. São Paulo: Cortez, 2002.

SHULMAN, L. Those who understand: knowledge growth in teaching. Educational Researcher, Washington, DC, v. 15, n. 2, p. 4-14, Feb. 1986.

SKOVSMOSE, O. Desafios da educação matemática crítica. São Paulo: Papirus, 2008.

TARDIF, M. Saberes docentes e formação inicial. Petrópolis, RJ: Vozes, 2002.

Neura Maria De Rossi Giusti, doutoranda em Ensino de Ciências e Matemática na Universidade Luterana do Brasil (Ulbra), é professora na Educação Básica, com experiência há mais de 25 anos no ensino público e desenvolve atividades, na área técnica de programas e projetos, na Secretaria Municipal de Educação de Vacaria, Rio Grande do Sul, RS, Brasil. neurajusti@ibest.com.br

Jutta Cornelia Reuwsaat Justo, doutora em Educação pela Universidade Federal do Rio Grande do Sul (UFRGS), é professora do Programa de PósGraduação em Ensino de Ciências e Matemática e do Curso de Pedagogia da Universidade Luterana do Brasil (Ulbra), Canoas, Rio Grande do Sul, RS, Brasil.

jcrjusto@gmail.com

Recebido em 28 de abril de 2013.

Aprovado em 3 de dezembro de 2013. 